\title{
Cultural districts and territorial development: the New Forest National Park
}

\author{
A. Villacampa \& C. Brebbia \\ Wessex Institute of Technology, UK
}

\begin{abstract}
Society has recently started to focus on how cultural planning can improve the development of a territory promoting tourism, manufacture, arts and crafts and the growth of local settlements. This contemporary approach takes into consideration the management of the resources of a territory including new regulations for social and economical improvements based on a sustainable intervention and administration of the land. Landscape is nowadays considered as a material heritage that has to be protected and developed. These requirements have introduced the concept of landscape planning as a tool for re-concealing competing land uses while protecting natural processes and significant cultural and natural resources. This way, the identity of a territory can be defined, protected and managed by local authorities, public administration and its own inhabitants. The involvement of local communities in a territorial network offers visitors a major enjoyment of the national parks and protected areas related to these ecosystems. The idea of a cultural district based on landscape heritage is an asset for territorial improvement with consequences for urban settlements growth, architecture and transport. The regulations required by cultural green districts for their proper management imply many stakeholders. The aim of this paper is to identify, analyze and classify these actors for a better understanding of the territorial system of a green district. The paper will focus on the New Forest National Park due to its origins and ancient existence. The importance of the context of the New Forest will be exemplified by a particular case study: the Wessex Institute of Technology as an illustration of conservation and integration with the environment.
\end{abstract}

Keywords: cultural planning, territorial development, territorial management, national park, cultural heritage, landscape planning, green district. 


\section{Introduction}

The beauty and history of the New Forest, nearby Southampton (UK), have always impressed visitors and locals all through the years. As different from many other historical parks in Britain, the New Forest is the home of numerous people and this makes it a more dynamic environment.

Since its origins in the $11^{\text {th }}$ century, the New Forest has been royal hunting grounds, a source of timber to the nation, space for grazing cattle, producer of minerals and charcoal and more recently a place dedicated to leisure activities. All different uses of the Forest have generated numerous industries since Roman times [1]. Thanks to this diversity of uses and ever changing activities it is not a contradiction to analyse the New Forest from the prospective of a cultural district that is part of a larger territorial structure.

In recent years, cultural planning is being considered a tool for the territorial development of a region able to generate tourism, civil and political public image, education, collective identity and social inclusion. Nevertheless, this growth model requires management strategies and regulation plans for the territory to reach coherent and sustainable interventions [2]. All the different actions that can be carried in a cultural planning process become this way a valid tool for territorial management. These actions -tutelage, conservation, valorisation, management, promotion and fruition- have to be connected with public policies (mainly cultural ones) with specific tools for territorial actions. In the case of the New Forest the basic tool for the territorial management is the LEADER European Program for rural development administrated through the New Forest Council and the New Forest National Park Authority whose procedures are inserted in the European Agricultural Fund program for Rural Development by the European Union [3].

\section{Brief history of the Nova Foresta and the inhabitants}

The so designated Nova Foresta by the first Norman King of England, William "the Conqueror", was a land too poor for intensive agricultural exploitation but provided good hunting goods. Back in history, although a large number of ancient burial barrows dating from the Bronze Age still exist, the forest appears to have always been sparsely populated [1]. The ancient inhabitants of the Forest were Celts displaced by the Romans from Belgae tribes in the continent that crossed the Channel in the $1^{\text {st }}$ century BC. During the Roman times, the main industry of the Forest may have been pottery as the numerous kilns prove. After this period, the Jutes settled in there until the Saxon invasion at around 500 AD. After the Normans invasion in 1066 AD, William "the Conqueror" established the New Forest near Winchester -where he was crowned- defining its boundary, establishing the Forest Law and carrying out forestation works for the royal household. The extent of the original Forest was much larger than now: the total area was around 150,000 acres compared with the present area of 90,000 acres, of which approximately 60,000 are in the hands of the Forestry Commission and 30,000 in private hands [1]. 
Much of the lost ground has been taken away by the development of towns and villages around the periphery. By the time of Richard I, the Forest became a source of timber and firewood as well as pasture. With Henry VI, the importance of the timber production immediately began to increase due to the naval production at Portsmouth and the Solent while its function as a hunting ground began to decrease. Moreover, Elisabeth I instituted the present system of enclosures to protect the trees from the animals as the timber production was crucial for the construction of her navy. Other local industries of strategic importance were saltpetre and charcoal, both used in manufacturing the gunpowder. It was Charles II who tried to reintroduce wild board into the forest, which had disappeared during the $15^{\text {th }}$ century as the wolf, which became extinct around the $16^{\text {th }}$ century. By the end of the $17^{\text {th }}$ century the Forest was in a very bad state and the system of keepers had all but collapsed. It was during World War I when numerous campsites were established and manoeuvres took place over the whole area. During the World War II the Forest became a major military site, with several airfields, two bombing ranges and innumerable encampments [1].

\section{The Forest nowadays}

The New Forest National Park was created in March 2005 and the New Forest National Park Authority took up its full powers in April 2006. Ponies, cattle and pigs have shaped the unique landscape of the Park. Woodlands, rare heathland and a long coastline characterize the context (figure 1) [4]. The National Park Authority aims to preserve the wildlife and cultural heritage of the Park, as well as to promote opportunities for understanding and enjoyment of its special qualities. The Park Authority controls and regulates the whole area through the Park Management Plan [5]. Furthermore, foresters and inhabitants of the villages that are integrated in the New Forest area are coordinated at a local level under the authority of the New Forest District Council that offers services and attends its community members with special care on the environment, health needs, social requirements and cultural activities; all of them well defined in a five-year corporate plan. Moreover, vernacular and heritage architecture (figure 2) are taken under consideration for their preservation by the District Council as part as their mission of promoting and protecting the existing cultural legacy of the Forest. New buildings and services have to be controlled and approved by the competent bureau inside this network of authorities characterizing the life style of the foresters [2]. Nowadays, the region has a great offer of activities for visitors and tourists all over the year. The New Forest is a lively, working landscape with many walking routes, picnic sites and all kinds of facilities where local experts tell visitors about the history, geology, wildlife, gastronomy and folklore of the region. 


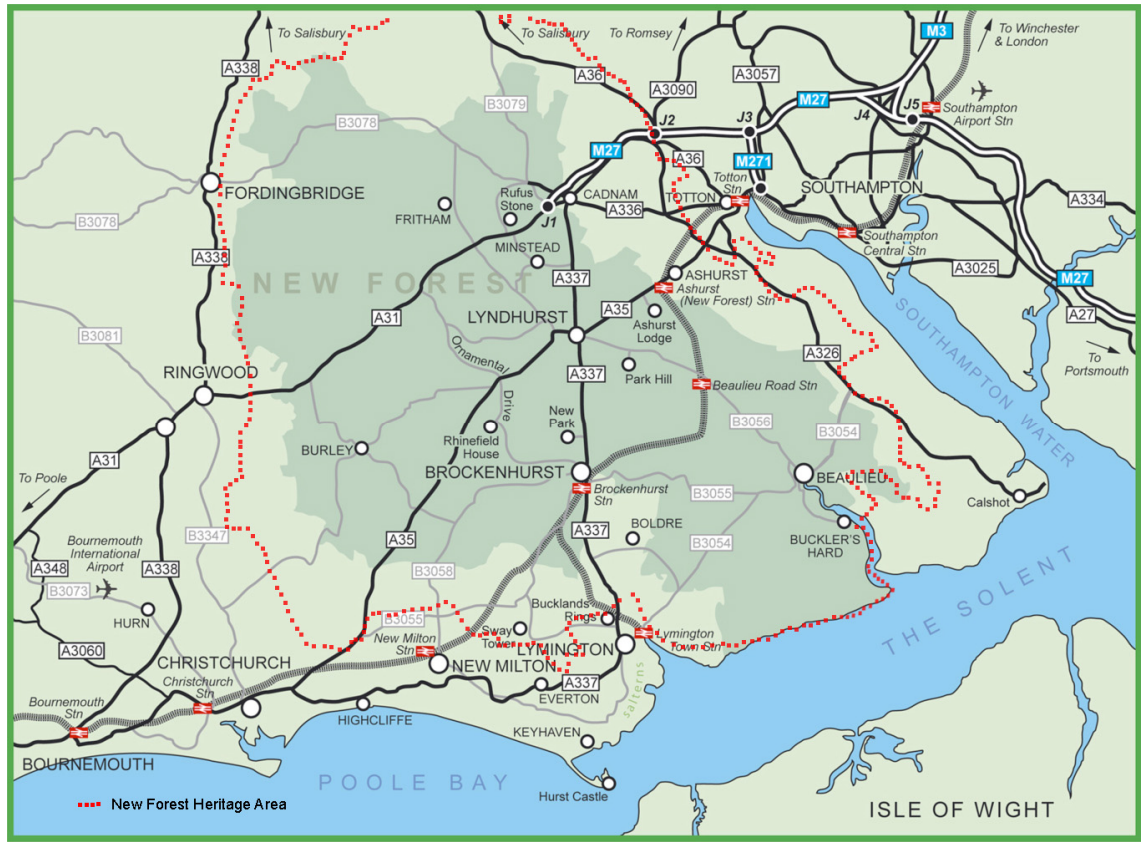

Figure 1: The New Forest National Park area nowadays.

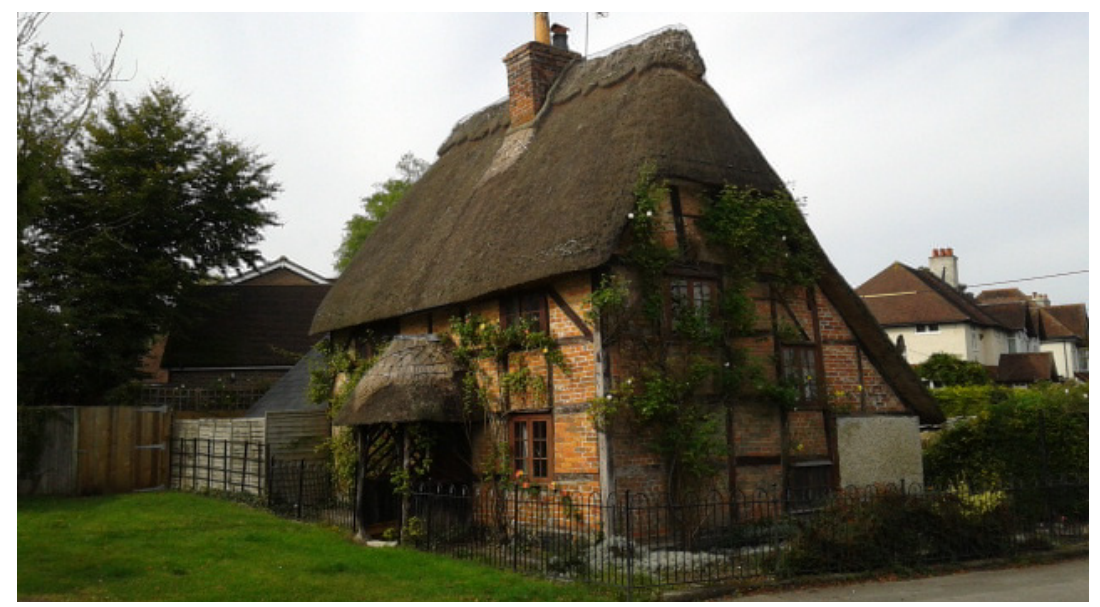

Figure 2: $\quad$ Traditional New Forest Cottage at Lyndhurst.

\section{Cultural planning and territorial development}

The Treaty of Maastricht (1992) opened a way to political integration. The agreement settled a European Union consisting of three pillars: the European 
Communities, Common Foreign and Security Policy, and police and judicial cooperation in criminal matters [6]. But the Treaty defines as well two principles for the concept of cultural planning: the first one establishes that culture is a tool for the European citizenship, the economical and social cohesion between its members, the labor generation in Europe, the elimination of the exclusion and the enrichment of the European life quality. With the so-called cultural clause, culture together with education and youth policies became an explicit part of European competencies. The second principle gives action priority to the "project culture", understood as a construction of possibilities procedure in any ambit of operation, including culture [2]. This way one can define the cultural planning process as the group of operations and actions that are able to promote -in the ambit of cultural policies- the "culture of the project" declared as a priority by the European Union and made operative through the use of the Project Cycle Management (figure 3).

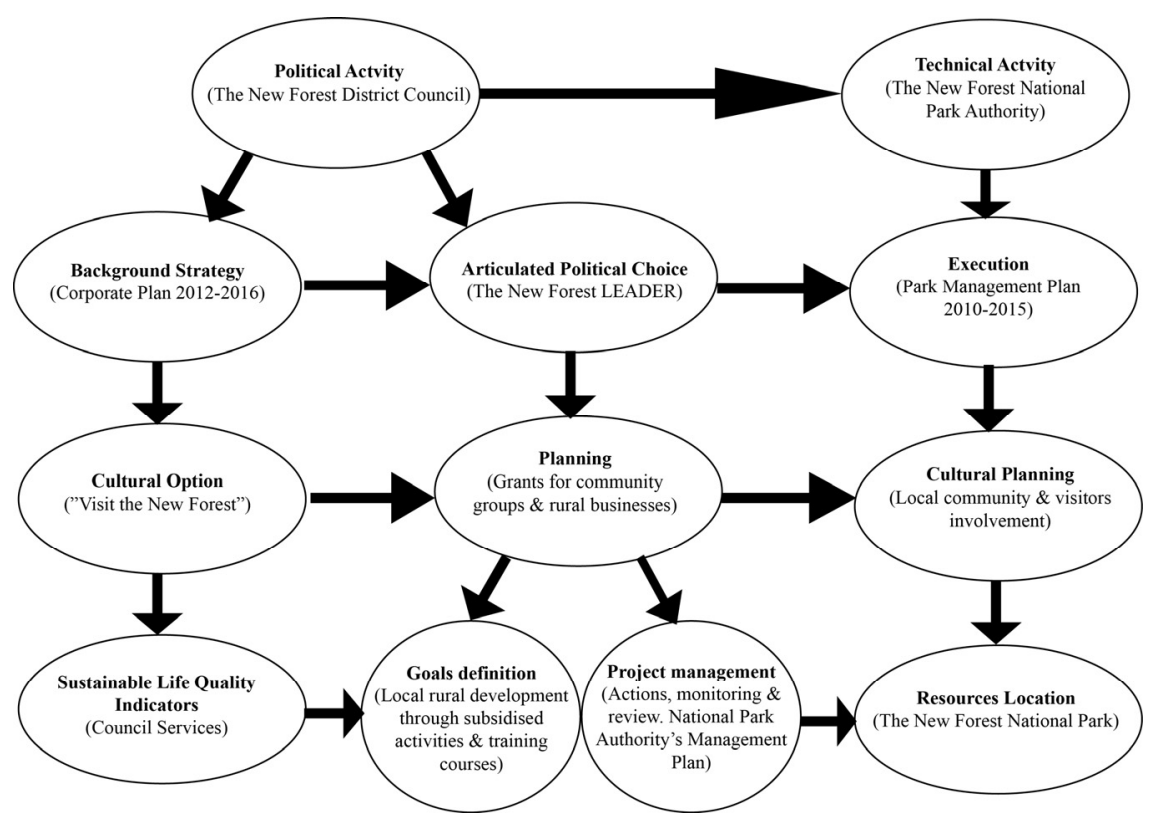

Figure 3: Political and technical activity for cultural planning. Adapted from Dalla Libera and Schunk [7].

Within this context, the nature of the cultural project must focus on the territorial development and has to be understood as an overall of institutional and social policies that interact with each other having the community as their target (figure 3). This way, the cultural planning activity - read as a dynamic process within a limited period of time where a limited amount of resources are invested to reach certain goals - can act through six specific actions: tutelage, conservation, valorisation, management, promotion and fruition. Furthermore, defining the limits of a cultural planning activity means to identify and represent 
the relationships between: a) a general plan in a territorial, social and financial scale and b) a cultural development plan. Through this procedure, the activity of cultural planning can become one of the factors for the development and growth of the territory. In order for this, the cultural planning activity, considered from the development point of view, must be integrated inside the territorial policies. This can lead to the preventive evaluation of the impact -environmental, social and economical- of a specific cultural development plan for a certain territory.

\section{Cultural and territorial identity of the New Forest}

The characterization of a territory's cultural identity as part of the cultural planning actions is a valid tool to establish territorial resources management policies. This cultural identity can be described through five aspects that will be an asset for the stakeholders to develop cultural actions as a priority for the territorial interest [2]:

1. The system and the context. Cultural heritage, history, arts, ethnography, ecosystems and environment are defined, protected and accomplished by the New Forest National Park Authority through their management plan and promoted by the New Forest District Council through different communication strategies.

2. Identity and participation of the population in the conservation and protection of the territorial culture. Thanks to the creation of the New Forest Marque as a sign of identity for local production, visitors and foresters can identify high quality manufactured local products and services. This brand has been extended to the New Forest Breakfast and is completed by a list of official local product markets with a coordinated schedule for each season and location.

3. Information and education. This aspect establishes a communication process with the inhabitants based on the knowledge of local identity, its spread and constant education. Building techniques such as timber-framed buildings, cob walling and lime plastering are very common in the New Forest. Grants from the New Forest RDPE (Leader) program allow the New Forest National Park Authority to offer subsided training courses for these types of skills and techniques. The rich cultural heritage of the Forest has a wide range of historic buildings with a high demand from property owners for craftsmen with traditional skills and an understanding of reparation and maintenance of these buildings. Those heavily subsidized courses offer specialized workshops for local building companies and architects but also open up new work chances for regional craftsmen [8].

4. Social and economical values. Economic resources of the territory can facilitate a sustainable development and social integration. A partnership of the New Forest Local Action Group, the New Forest District Council and the New Forest National Park Authority successfully established from January 2008 a funding program from the EU's RDPE (Leader) Program 2008-2013. The New Forest RDPE (Leader) supports specific types of capital investment in farming, forestry and horticultural businesses as well as small rural businesses which are 
land based or add value to local produce, encouraging alternative energy technologies as part of the development process [3].

5. Structure and project. Tutelage and valorisation of the cultural heritage are a goal for local policies and a tool for local action plans. In this case The National Park management Plan 2010-2015 has established ten specific actions: conservation of local distinctiveness, enhancement of landscapes and habitats, sustainable land management encouragement, climate change planning, safeguarding tranquillity, special qualities understanding, enjoyment of the National Park, local communities support, fostering economic well-being and improvement of traffic and transport [9]. All these steps are monitored and evaluated during a five-year planning period to propose reviews and future improvements.

The economical profile of the New Forest District Council (NFDC) [13] shows that $29 \%$ of employments by sector corresponded to distributions, hotels and restaurants sector while $21.7 \%$ are in public administration, education and health sector, and $17.8 \%$ of the total employment was located in the banking, finance and insurance sector. According to Census 2001, of these employments by sector, $31.9 \%$ of a total of 77,054 employees of the main sector (hotels and restaurants) is New Forest residents. In addition, the NFDC had in 2009 a $12.2 \%$ of self-employees in front of the $9.5 \%$ national average and higher than the average in the whole Hampshire Council (10.3\%). This situation (prior to the current recession started in 2008) shows how the territorial development of the New Forest effectively focused on an economical development based on tourism (figure 4).

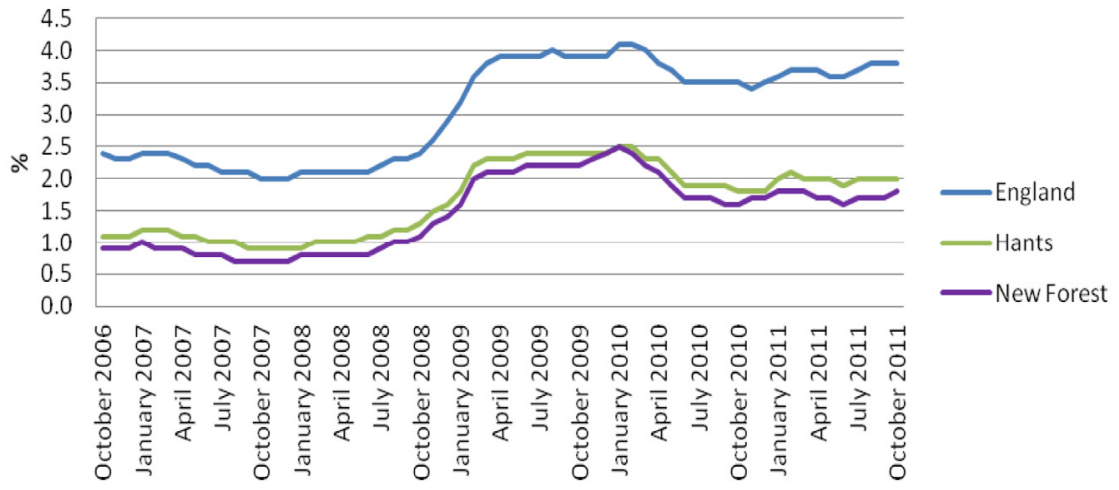

Figure 4: Geographical comparison of unemployment in the New Forest. Source: NOMIS [4].

\section{Sustainable territorial development}

The understanding of a territory as a "cultural district" aims a more efficient planning of all the activities and cultural services enhancing -at a local scale- the economical and social impact that can derivate from this. 
To achieve a sustainable development applied to a cultural heritage requires some attention to the difference between growth and development. The concept of growth only takes into account economical indicators. The concept of development comprehends the logic of public policies as indicators of life quality; social, educational and economical development opportunities; social capabilities and resources production and reproduction. Cultural development nowadays includes the preservation of the heritage and life of a territory for future generations (figure 5). This sustainable development can be understood as responsible valorisation within a context of human resources, where the participation of the benefits and contribution of the inhabitants is carried in an environment of social cohesion [2].

\begin{tabular}{|c|c|}
\hline The New Forest National Park & \\
\hline forest area $\&$ heritage area & 139,520 acres $(56,658 \mathrm{Ha})$ \\
\hline woodland & 55,040 acres $(22,379 \mathrm{Ha})$ \\
\hline heathland \& grassland & 39,040 acres $(16,000 \mathrm{Ha})$ \\
\hline farmland & 36,480 acres $(14,849 \mathrm{Ha})$ \\
\hline coastline & 26 miles $(42 \mathrm{Km})$ \\
\hline Sites of Special Scientific Interest (SSSI) & 79,360 acres $(32,103 \mathrm{Ha})$ \\
\hline ancient monuments & 214 \\
\hline listed buildings & 610 \\
\hline public footpaths & 146 miles $(235 \mathrm{Km})$ \\
\hline population & $34935(61 \mathrm{ppl} / \mathrm{sqKm})$ \\
\hline $\begin{array}{l}\text { Number of parishes and towns wholly or partly } \\
\text { within the Park }\end{array}$ & 37 \\
\hline
\end{tabular}

Figure 5: The New Forest National Park figures. Source: NF Park Authority, 2012 [4].

Sustainability can only be conceived with a parallel growth of social capabilities and requires the involvement of all the community members and the political support of territorial policies. Integrative programs - like the EU's RDPE (Leader) Program 2008-2013; DEFRA's programmes [10]; the South East England Development Agency (SEEDA); the European Agricultural Fund for Rural Development (EAFRD) [11] and the European Regional Development Fund (ERDF) [12] - designed with and for the community are able to solve problems related to the governance of the territory.

Furthermore, the Territorial Integrated Projects (TIP) is a complex of integrative actions, linked and coherent to each other, with the common aim of the development of the territory. These actions justify a unitary performance approach. The TIP is thus made of project components that are specifically linked to the common territorial development (figure 6). A very effective TIP in the case of the New Forest is the improvement of communications and public transport. Train, mainly from the centre of London and airports, can easily reach 
the area. Railways communicate the main urban settlements of the territory and there is a public bus service with tourist routes for visitors with stops on every station. This fact has improved the services for commuters and brings visitors to the territory during the whole year in a sustainable way. The presence of two international airports (Bournemouth, and Southampton) on the periphery of the New Forest has significantly improved the economical development. In addition, many cruise liners have their base in Southampton and ferries from the continent arrive to main ports like Bournemouth, Portsmouth and Plymouth. All this network of services can support the territorial integration and improve the economy of the region.

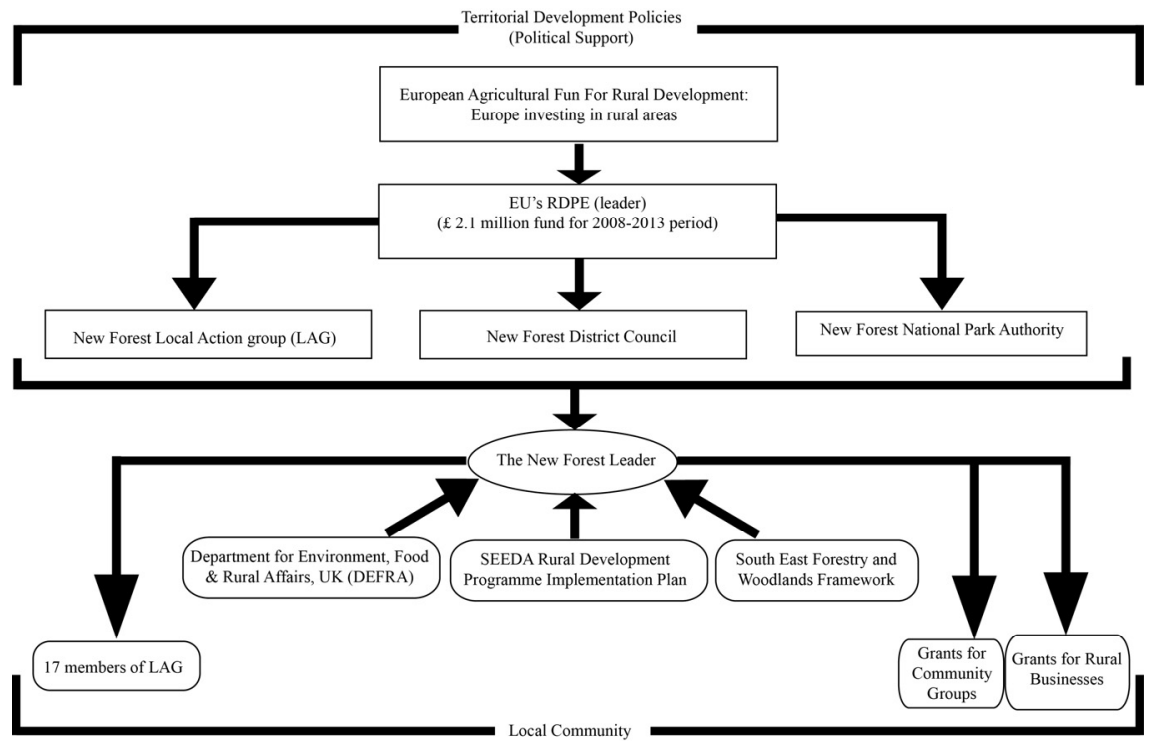

Figure 6: Territorial Integrated Project (TIP) network for the New Forest [2].

\section{A case study of integration in the territorial development of the New Forest: Ashurst Lodge}

The territorial development of the New Forest includes many activities and services that have settled in the National Park area as part of the cultural development network. One of those actors is located in Ashurst Lodge, where a group of heritage buildings have been adapted to become the headquarters of scientific research activities. The architecture of the complex respects the traditional style of the buildings that host the headquarters of the Wessex Institute of Technology (WIT). The location is completed with residential buildings where researchers and families enjoy the forester life style [1].

From the A35 (an important track connecting Lymington to Southampton) Ashurst Lodge can be reached by a private road from where it can be appreciated 
that a large saltpetre factory existed. It is reasonable to assume that some early habitation may have existed there since some remains of Roman pottery have been found nearby and due to its excellent position. After the middle of 1584 the land returned to open forest due to the failure of saltpetre production. From then on a series of Forest Keepers took up residence in the Lodge and treated the occupied land as their own private property obtaining considerable profits. In 1708, Ashurst Lodge was burnt to ground, together with its outhouses and stables. It needed to be completely rebuilt this time in brick, which was the trend after the Great Fire of London in 1667. The earliest surviving plans of Ashurst Lodge, dated in 1784, show it as a rectangular building of approximately $26 \mathrm{ft}$ by $43 \mathrm{ft}$ in plan $(8 \mathrm{~m}$ by $13 \mathrm{~m}$ ) with a small porch and an attached wash house. By 1853 , a dairy had been added to the ground floor with a cellar below. From then, substantial changes were made to the building until the $20^{\text {th }}$ Century when Ashurst Lodge ceased to be used by the Forest officers becoming a family house from the beginning of 1921 when two new wings were added. The Lodge also played an important role in the planning of the Normandy invasion when it became the headquarters of a Mulberry Harbour design unit, a team of engineering officers and the support staff were positioned there at the PLUTO project [1].

Wessex Institute of Technology moved to Ashurst Lodge in 1982 and since then the group has continued to develop the premises in a sympathetic manner. WIT was established to act as a link between academia and industry; an institution dedicated to advanced technology and scientist knowledge being a pioneer successfully introducing high quality research activities in the natural environment of the Forest. Every year scientists, researchers and conference delegates join the institution discovering the importance of the heritage of the Park [1].

\section{Conclusion: the Forest is the Venue}

The importance of a territorial development is directly related to what kind of economical activities are involved, the existence of a network of stakeholders and the management of its resources. All these factors contribute to create a territorial identity that can be promoted in diverse ways to generate benefits at many levels. As it has been previously said, in the case of the New Forest, the National Park Authority and the District Council manage the resources of the territory: the first one protects its natural value and the second is in charge of developing social and political activities. The stakeholders of the network have different backgrounds as, for instance, leisure activities, farming, arts and crafts, education or culture. The right combination of all these layers through the Project Cycle Management brings a proper territorial development where the Forest is the Venue. This way, the local community becomes conscious of its valuable resources and its members interact with each other providing services and products that, on the next level, can be used for the promotion of the cultural district with a proper corporate identity and reach different target groups. The overall goal is not only the preservation of the Forest as a Natural heritage but 
also the promotion of the network as a cultural district through its products and services. Among the diversity of activities, products, businesses and services that the New Forest's territorial network has the paper has focused on the cultural and research activities developed by the Wessex Institute of Technology (WIT). In this particular case, an international research institute has settled in such a specific context becoming part of a territorial network mainly focused of tourism, gastronomy, farming and crafts. The origins of WIT's architecture and location are part of the historical growth of the forest; this fact is taken into account for any building improvement and architectural refurbishment. Thanks to its location, the activities of the Institute encourage academic life and it is a starting point for international delegates to explore the territory. The diversity of visitors to WIT's meetings support the territorial network by using infrastructures such as hotels, bed and breakfasts or restaurants promoting tourism at the same time.

In the same way, the Institute uses the Territorial network as a source of specialized local manufacturers; collaborates to maintain the forestry and its members are fully integrated into the local community.

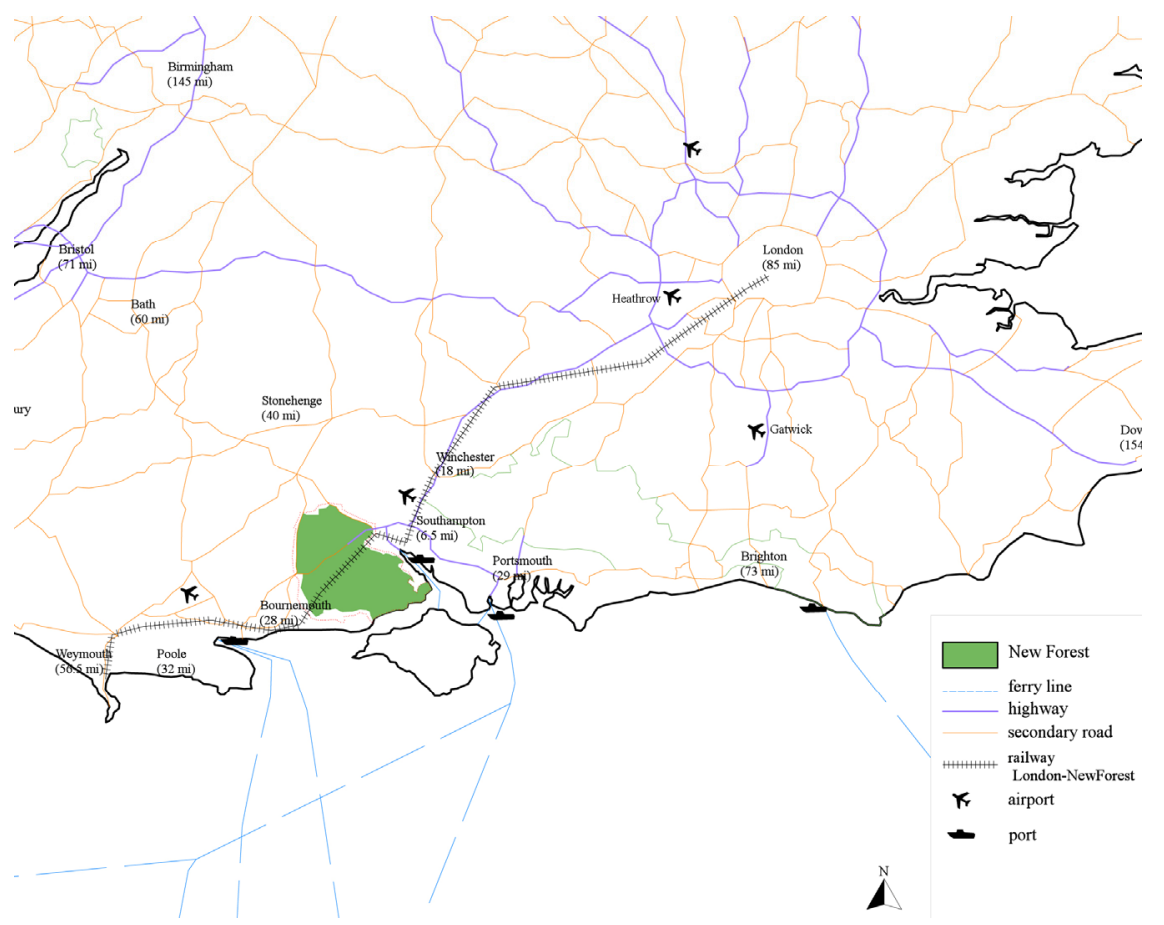

Figure 7: South of England map: NFNP, green areas and main communications.

The territorial development of this cultural district is relatively recent and the identity of the network is being consolidated thanks to the contribution of the 
foresters to preserve this legacy and take its benefits; this is reflected on the use of the New Forest marque as a warranty of quality. This territorial development has been supported by good infrastructures (figure 7) that consolidate the given actions.

Furthermore, investing in "integrated landscape approaches" achieves sustainable development. Well-managed forests have the potential to stimulate economic development and contribute to a healthy local and global environment. This way the New Forest is an example of how a properly valued and wellmanaged territory can upgrade its potentials following three main goals: territorialisation, economical and social development. All these facts confirm that the Forest is the venue where all the layers and actors of the cultural district meet as the consequence of a well-structured territorial development plan.

\section{References}

[1] Brebbia, C.A. The New Forest: A personal view. WIT Press, Southampton (UK), 2008

[2] Amari, M. Progettazione culturale. Metodologia e strumenti di cultural planning. Franco Angeli Editori. Milano, 2006

[3] New Forest Leader [on-line] 2008-2012 v1.0 http://www.newforest leader.org.uk/index.cfm? articleid $=8375 \&$ CFID $=16580864 \&$ CFTOKEN= 73084421

[4] The New Forest National Park Authority [on-line] 2012 http://www.newforestnpa.gov.uk/

[5] The New Forest National Park Management Plan 2010-2015; The New Forest National Park Authority, [on-line] March 2010 http://www.newforest npa.gov.uk/about-us/our-work/publications/managment-plan-2010-2015

[6] Treaty of Maastricht on European Union October 2010 [on-line] http://europa.eu/legislation_summaries/institutional_affairs/treaties/treaties maastricht_en.htm

[7] $\bar{D}$ alla Libera, L. Schunk, J. Pogettare la cooperazione allo sviluppo-appunti di lavoro. Quaderni per la pace n.2, UNIP, Trento, 1999

[8] Keeping traditional building skills alive. The New Forest National Park Authority, 2012 [on-line] http://www.newforestnpa.gov.uk/news/newsreleases/news-releases-2012/keeping-traditional-building-skills-alive

[9] Chapter 4. Taking action; The New Forest National Park Management Plan 2010-2015; pp. 17-58; The New Forest National Park Authority, March 2010 [on-line] http://www.newforestnpa.gov.uk/about-us/our-work /publications/managment-plan-2010-2015

[10] Department for Environment, Food and Rural Affairs (DEFRA) 2012 [online] http://www.defra.gov.uk/

[11] European Agricultural Fund for Rural Development (EAFRD), 2012 [online] http://europa.eu/legislation_summaries/agriculture/general_framework /160032_en.htm 
[12] European Regional Development Fund (ERDF); 2012 [on-line] http://www.communities.gov.uk/regeneration/regenerationfunding/europea nregionaldevelopment/

[13] The New Forest District Council, ABI, 2001 